\title{
Estudos Asiáticos no Brasil: contexto e desafios
}

\author{
Asian Studies in Brazil: context and dilemmas
}

HENRIQUE ALTEMANI DE OLIVEIRA*

GILMAR MASIERO**

Rev. Bras. Polít. Int. 48 (2): 5-28 [2005]

\section{Introdução}

No início dos anos 60, a partir da constatação de perspectivas divergentes, Estados Unidos envolvido com as questōes da segurança internacional e Brasil voltado para a busca de instrumentos que possibilitassem seu desenvolvimento econômico, a política externa brasileira entrou num processo de alteração de seu paradigma anterior, baseado numa aliança estratégica com os Estados Unidos. Foi fundamental neste processo, de um lado, a perspectiva de diversificação de parceiras, econômicas e/ou políticas e, de outro, a aceitação das teses do Terceiro Mundo, em especial a necessidade da definição de uma Nova Ordem Econômica Internacional.

Neste sentido, no estudo do relacionamento brasileiro com a Ásia, alguns pontos merecem destaque especial. O discurso favorável a modificações na ordem internacional e, em especial, a imersão na proposta de Cooperação SulSul, aponta a existência de interesses e valores comuns entre o Brasil e a Ásia. No período da Guerra Fria, entretanto, a aproximação brasileira foi, na prática, muito mais direcionada para os países africanos e para o Oriente Médio. ${ }^{1}$ A exceção foi o relacionamento, mais intenso no plano político, com a China, após sua reintegração no sistema internacional no início dos anos 70 . Já a relação com o Japão, dentro do conceito de diversificação, sempre foi considerada como uma alternativa ao relacionamento com os Estados Unidos.

No pós-Guerra Fria, a manutenção das orientações básicas da política externa brasileira e o dinamismo econômico asiático, entre outros fatores, vão

\footnotetext{
* Professor de Relações Internacionais da Pontifícia Universidade Católica de São Paulo - PUC/SP e coordenador do Grupo de Estudos Ásia-Pacífico da mesma universidade (henrique.altemani@gmail.com).

** Professor e Pesquisador da Universidade Estadual de Maringá e Membro do Grupo de Análise da Conjuntura Internacional da Universidade de São Paulo - Gacint - USP (g_masiero@yahoo.com).

${ }^{1} \mathrm{O}$ papel do mundo afro-asiático está muito bem retratado nos trabalhos de MENEZES, Adolpho Justo Bezerra. O Brasil e o mundo ásio-africano, Rio de Janeiro: Irmãos Pongetti, 1956 e SELCHER, Wayne. The Afro-Asian dimension of Brazilian foreign policy (1956-1972). Gainesville: University Presses of Florida, 1974.
} 
propiciar a perspectiva de se buscar uma maior aproximação com a Ásia. O pouco interesse dos Estados Unidos em ampliar seus intercâmbios comerciais com países latino americanos no final do século passado, com exceção do México, também tem pressionado o Brasil a buscar um maior relacionamento com outros países. Neste cenário, a ampliação e a implementação de um relacionamento mais intenso com a Ásia se apresenta fortemente dependente das iniciativas governamentais. Nelas se observa uma presença atuante da sociedade civil em sua definição, esta, porém tem sido mais direcionada para as questôes regionais e hemisféricas do que para a distante e relativamente desconhecida Ásia. ${ }^{2}$

Em seu atual projeto de inserção internacional, o Brasil delega à região asiática um espaço especial, considerando-se a grande demanda por investimentos e por acesso a tecnologias de ponta, bem como por um mercado com alta capacidade de consumo. Historicamente, o Brasil suscita interesses na Ásia por se caracterizar como uma importante fonte supridora de matérias-primas, principalmente produtos alimentícios e insumos básicos. Nesse sentido, na medida em que a Ásia se dinamiza e se especializa em produtos manufaturados, é mantido ou ampliado o interesse na importação de produtos básicos do Brasil.

Além de país fornecedor de matérias-primas para a rápida industrialização de alguns países asiáticos, principalmente na segunda metade do século passado, o Brasil já possuía laços de amizade e fluxos migratórios com vários países asiáticos que datam do século XIX. Apesar deles, até a década de 1970 o relacionamento brasileiro com a Ásia restringia-se basicamente às relações com o Japão, com a aproximação, de caráter mais político e com a República Popular da China a partir da metade dos anos 1970. Mesmo esse restrito relacionamento sofre uma retração com a sucessão de crises nos anos 1980, retomando força na década de 1990.

$\mathrm{Na}$ última década, a retomada e ampliação do relacionamento com a Ásia adquirem novo vigor pela maior presença tanto da Coréia do Sul e dos países do Sudeste Asiático, quanto da China que, em decorrência de seu desenvolvimento acelerado, não mais é só um ator político, mas um forte mercado consumidor além de fornecedor.

Nos anos 90, por exemplo, a Coréia do Sul, particularmente com seus grupos Samsung e LG, surgiu como um grande protagonista de investimentos diretos direcionados ao setor eletroeletrônico. Nos primeiros anos do presente século, têm sido crescentes os investimentos chineses, como nos casos da empresa Huawei, fornecedora de equipamentos de telecomunicações, do Grupo Shangdong, na área de geração de energia termoelétrica e o Grupo Shangai Baosteel em uma joint venture com a Companhia Vale do Rio Doce para a

\footnotetext{
2 Em decorrência da imprecisão do termo “Ásia”, a regiāo que estará sendo abordada nesta reflexão corresponde à "Ásia-Pacífico" ou ao "Leste Asiático", englobando o Nordeste Asiático (Japão, China, Hong Kong, Taiwan, Coréia do Sul e Coréia do Norte), e os atuais membros da Asean - Associação das Naçōes do Sudeste Asiático - (Indonésia, Malásia, Tailândia, Filipinas, Cingapura, Brunei, Vietnã, Laos, Camboja e Myanmar).
} 
mineração de ferro e aço. ${ }^{3}$ Esta retomada tem clara conotação econômica, mas também é influenciada pela disputa comercial entre os países desenvolvidos e pela proposta de criação de uma Área de Livre Comércio das Américas (Alca), por muitos entendida como uma modalidade de protecionismo regional, com entraves para a inserção de atores externos.

Apesar do aumento do dinamismo político e econômico entre o Brasil e os demais países asiáticos, detecta-se baixo ou esporádico envolvimento acadêmico com essas conexões inter-regionais. Os esforços despendidos até recentemente estiveram basicamente concentrados na análise do relacionamento com o Japão ou sobre o modelo de desenvolvimento japonês. ${ }^{4}$ Destarte, análises sobre este relacionamento tendem a ser esporádicas, seletivas e desiguais, sendo o número de pesquisadores envolvidos extremamente reduzido, com praticamente inexistente participação de recursos institucionais.

Persiste, neste sentido, um profundo vácuo informativo, de desconhecimento das respectivas regiōes. Buscando contribuir para estreitar este distanciamento, o presente trabalho procura sintetizar a história das relações do Brasil com a região asiática; evidencia os esforços de algumas instituições e acadêmicos no estudo deste relacionamento concentrando sua atenção aos aspectos políticos e econômicos; e, finalmente, discute as perspectivas e possibilidades de crescimento das relações acadêmicas entre brasileiros e asiáticos como forma de consolidar e ampliar as iniciativas em curso.

\section{O desenvolvimento das relações do Brasil com a Ásia-Pacífico}

Até quase o final do século XIX pode-se afirmar que não havia qualquer tipo de relacionamento entre o Brasil e a Ásia. Quando do início da busca de mão-de-obra para substituir a força de trabalho escrava no Brasil, a opção era por mão-de-obra chinesa, motivando o deslocamento de uma missão brasileira para a China em 1879. Mesmo com a não concretização dessa corrente migratória, pela proibição formal da China em permitir emigração para o Brasil, os dois países assinaram o Tratado de Amizade, Comércio e Navegação em 1881, com o Brasil abrindo um consulado em Xangai em 1883.

A razão da não permissão de vinda de mão-de-obra chinesa ao Brasil decorre essencialmente dos maus tratos que as primeiras correntes migratórias para o continente americano tinham sofrido, em especial em Cuba, no Peru e na Califórnia

\footnotetext{
${ }^{3}$ Ver MASIERO, Gilmar. Investimentos diretos do Japão, Coréia do Sul e China no Brasil: motivos, características e perspectivas. Texto preparado para o II Encontro de Estudos Coreanos na América Latina. México. Outubro de 2005.

${ }^{4}$ Ver, entre outros, TORRES FILHO, Ernani T. A economia politica do Japão: reestruturação econômica e seus impactos sobre as relaçôes nipo-brasileiras (1973-1990). Rio de Janeiro: Tese de Doutorado, Instituto de Economia Industrial, 1991. MASIERO, Gilmar. Empresas Japonesas: Estrutura, Principais aspectos e processo decisório. São Paulo, EAESP-FGV, 1994. SCHWARTZ, Gilson (org). Liçôes da Economia Japonesa. São Paulo: Saraiva, 1995.
} 
(Estados Unidos). De outro, o fato do tratado assinado entre Brasil e China seguir o modelo dos firmados pela China com as potências ocidentais (denominados de tratados desiguais), também não facilitou o acordo migratório. Cervo e Bueno apontam que a missão brasileira, em seus preparativos, se encontrara "na Europa com os governos ocidentais em busca de apoio e levava instruções específicas para não discordar nas cláusulas a convencionar de nenhum direito já outorgado anteriormente pela China, tendo em vista manter a simpatia e o consenso das nações amigas". 5

Com a China, os contatos bilaterais foram escassos em decorrência da sucessão de conflitos internos e externos que afetaram aquele país no final do século XIX e na primeira metade do século XX. Com a vitória de Mao Zedong em 1949, o Brasil rompeu as relações diplomáticas. Mesmo assim, registra-se durante o século XIX a entrada oficial no território brasileiro de aproximadamente 3.000 chineses. $^{6}$ Após 1949, constata-se a intensificação de um fluxo migratório chinês, não oficial para o Brasil, em especial para a cidade de São Paulo. Possivelmente, estes imigrantes deixavam a China por não aceitarem as regras do novo regime que se instaurava com a instauração da república socialista.

No que se refere ao Japão, somente com a Restauração Meiji (1867) é que o Japão passou por uma série de modificações estruturais que possibilitaram o estabelecimento do Japão moderno e também uma abertura para o exterior. Em decorrência da Restauração, a economia japonesa sofreu um processo de desestabilização provocando fluxos migratórios inicialmente para o Havaí e a costa oeste dos Estados Unidos. Do lado brasileiro, com a abolição da escravidão em 1888 e com o crescimento rápido da lavoura cafeeira no Estado de São Paulo tornou-se necessária à ampliação da migração de mão-de-obra externa. Dessa forma, o relacionamento bilateral entre o Brasil e o Japão iniciou-se com a vinda de migrantes para o trabalho nas lavouras cafeeiras. A base legal para esse relacionamento foi criada, primeiramente, pela assinatura do Tratado de Amizade, Comércio e Navegação em novembro de 1895 e, depois, pelo estabelecimento de companhias que trabalhavam especificamente no recrutamento e transporte de emigrantes.

A chegada do navio Kosato Maru, em 1908, deu início à imigração japonesa ao Brasil, tendo um crescimento significativo até 1934 quando a nova Constituição brasileira limitou o fluxo migratório, o qual praticamente se interrompeu com a Segunda Guerra Mundial, sendo retomado somente após $1955 .^{7}$ Em quase um

5 CERVO, Amado Luiz \& BUENO, Clodoaldo. História da política exterior do Brasil. São Paulo: Ática, 1992. p. 123. Sobre essas questōes do tratado e da busca de mão-de-obra chinesa, veja também: DANTAS, Fábio Lafaiete. Origens das relações entre o Brasil e a China: a missão especial de 1879. Brasília: Dissertação de Mestrado, Universidade de Brasília, 1986; BUSSCHE, Eric Vanden. A dimensão histórica das relações sino-brasileiras (séc. XVI-1943). In: Tempo Brasileiro, n. 137. p.85-98; SPENCE, Jonathan. Em busca da China moderna: quatro séculos de história. São Paulo: Companhia das Letras, 1995. p. 216-221.

6 TEIXEIRA Leite, José Roberto. A China no Brasil. Campinas: Editora da UNICAMP, 1999. p. 111-124.

$7 \mathrm{O}$ processo de imigração japonesa foi detalhadamente analisado por LEÃO, Valdemar Carneiro. $A$ crise da imigração japonesa no Brasil (1930-1934). Brasília: IPRI, 1990 e SAITO, Hiroshi. A presença japonesa no Brasil. São Paulo: EDUSP, 1980. 
século da presença de imigrantes japoneses no $\mathrm{Brasil}^{8}$ foi grande sua contribuição para o desenvolvimento brasileiro. Esse esforço foi investigado pela antropóloga Ruth Cardoso9, que analisou a adaptação dos descendentes de japoneses à sociedade brasileira, especialmente à paulista.

O Brasil foi o maior receptor mundial de imigrantes japoneses ao longo do século passado, ultrapassando hoje, com seus descendentes, mais de um milhão de pessoas. O bairro da Liberdade em São Paulo pode ser considerado uma das maiores cidades japonesas fora do Japão. A presença de japoneses e seus descendentes é grande também no interior de São Paulo e nos Estados do Pará e do Paraná. Neste último, mais expressivamente na região norte do Estado, em cidades como Londrina, Maringá, Assaí e outras.

A presença nipônica no norte paranaense é visualmente percebida e academicamente documentada em vários trabalhos científicos desenvolvidos ao longo do tempo. Entre os trabalhos recentes temos a contribuição de Celina M. Murasse ${ }^{10}$ e Tereza H. de Rezende ${ }^{11}$. Destacam-se também os trabalhos de Ruy C. Wachowicz, ${ }^{12}$ e Evandir Codato ${ }^{13}$ como representativos do esforço paranaense na busca de um maior e melhor conhecimento dos diferentes processos migratórios e de aculturação de diferentes povos a também diferentes espaços geográficos.

Se o relacionamento com Japão e China data do Século XIX, com a Coréia do Sul é bem mais recente. ${ }^{14} \mathrm{O}$ relacionamento político-diplomático do Brasil com a Coréia do Sul teve início em junho de 1949. O Brasil foi o oitavo país do mundo e o segundo latino-americano (o primeiro foi o Chile) a reconhecer oficialmente aquele país asiático. Durante e após o conflito bélico na Coréia, o Brasil, a exemplo dos demais países latino-americanos, sempre votou favoravelmente à Coréia do Sul em questôes políticas ou comerciais perante instituições como as Nações Unidas e a atual OMC (Organização Mundial do Comércio). O Brasil, por meio do relacionamento de amizade com o governo coreano e comportamento cooperativo com os Estados Unidos, atendia os

${ }^{8}$ Comissão de elaboração da história dos 80 anos da imigração japonesa no Brasil. Uma epopéia moderna: 80 anos da imigração japonesa no Brasil. São Paulo: Hucitec/Sociedade Brasileira de Cultura Japonesa, 1992.

${ }^{9}$ CARDOSO, Ruth. O papel das associações de jovens na aculturação dos japoneses. São Paulo: Dissertação de Mestrado, Universidade de São Paulo, 1970; CARDOSO, Ruth. Estrutura familiar e mobilidade social: estudo dos japoneses no estado de São Paulo. São Paulo: Tese de Doutorado, Universidade de São Paulo, 1972. ${ }^{10}$ MURASSE, Celina M. Processo imigratório no século XX: duplo caráter da imigração japonesa no Brasil. São Paulo: Dissertação de Mestrado, Universidade Federal de São Carlos, 1993.

11 REZENDE, Tereza H. de. Ryu Mizuno: saga japonesa em terras brasileiras. Curitiba: SEEC; Brasília: INL, 1991.

12 WACHOWICZ, Ruy C. História do Paraná. Curitiba: Vicentina.1988. obrageiros, mensus e colonos: história do oeste paranaense. Curitiba: Vicentina, 1982.

13 CODATO, Evandir. Colonização agrícola: a colônia três barras - 1932-1970. Curitiba: Dissertação de Mestrado, Universidade Federal do Paraná, 1981.

14 Os cinco parágrafos seguintes sobre a imigração coreana foram anteriormente publicados no texto: MASIERO, Gilmar. A economia coreana: características estruturais. In: GUIMARÃES, Samuel Pinheiro (Org.). Coréia: visōes brasileiras. Brasília: IPRI, 2002. 
interesses deste último não só na península coreana, onde era necessário impedir a expansão do comunismo, como também na América Latina, onde era imperativa a manutenção da paz hemisférica.

Em 1965, o Brasil estabeleceu sua embaixada em Seul e em 1967 designou seu primeiro representante oficial naquele país, o embaixador Bartel Rosa. A partir dos anos 60, o governo coreano passou a intensificar sua atividade diplomática - acordos e missões comerciais - com países considerados comercialmente estratégicos. Em 1962, estabeleceu na cidade do Rio de Janeiro sua primeira embaixada na América Latina (a décima terceira no mundo). Mais tarde, em 1970, devido à maior demanda de serviços pelos imigrantes coreanos, instala, em São Paulo, o Consulado Geral.

De acordo com Lee, ${ }^{15}$ em janeiro de 1961 foi criada, na Coréia do Sul, uma associação de emigração. O golpe militar de 1961, na Coréia, comandado pelo general Park Chung Hee, despertou o interesse de muitos sul-coreanos pela emigração. Dessa forma, chegaram ao Porto de Santos, em fevereiro de 1963, um grupo de 103 sul-coreanos e, em novembro do mesmo ano, mais um grupo de 350 pessoas. Estes grupos foram assentados nas proximidades de Guarulhos e Mogi das Cruzes, no Estado de São Paulo. No ano seguinte, outros dois grupos, totalizando 635 sul-coreanos, chegam ao Brasil e se instalam em São Paulo e no Rio de Janeiro. Nos anos de 65 e 66 mais 1.065 chegaram ao Paraná e outros 3.032, que chegaram entre os anos de 67 e 70 , permanecem em São Paulo.

O maior número de imigrantes, 4.028, chegou ao Brasil em 71 e 72. Após esta data, de acordo com Choi, ${ }^{16}$ registram-se ainda outros 752 entre 73 e 79 e mais 848 entre 80 e 85 . Além do Brasil, os Estados Unidos, Canadá, Austrália e África do Sul eram as opções dos emigrantes sul-coreanos. O Brasil, naquela época, mais industrial e economicamente mais desenvolvido que a Coréia do Sul, apresentava-se como uma opção possível. O êxito da emigração japonesa em anos anteriores também contribuiu para que o interesse do governo e do povo coreano pelo Brasil fosse grande.

Em 1980, houve nova regulamentação da lei brasileira de imigração, e cerca de 4.500 sul-coreanos encontravam-se em São Paulo em situação irregular. Estes sul-coreanos e outros 2.500 em 1989, que ilegalmente entraram no país, via Paraguai, foram anistiados e tiveram sua situação regularizada. No início dos anos 90, a embaixada da Coréia do Sul divulgou que aproximadamente 43 mil sul-coreanos residiam no Brasil. A Revista Veja, em maio de 98, divulgou que o número de imigrantes legais chega a 45 mil e o número de ilegais, segundo estimativas da Polícia Federal, chega a 35 mil. A presença dos imigrantes

15 LEE, Sangki. Brasil e Coréia do Sul: aspectos político-econômicos do relacionamento bilateral. Brasília: Dissertação de Mestrado, Universidade de Brasília, 1995. p. 58-62.

16 CHOI, Keum Joa. Além do arco-íris: a imigração coreana no Brasil. São Paulo: Dissertação de Mestrado, Universidade de São Paulo, 1991. p. 34-37. 
coreanos certamente contribuiu para o aumento das transações entre os países, especialmente as que dizem respeito ao comércio bilateral.

Os fluxos migratórios de asiáticos para o Brasil mais expressivos foram os acima considerados. Os japoneses juntamente com seus descendentes são mais de 1,3 milhão os chineses cerca de 200 mil e os sul-coreanos, legalizados e ilegais, 80 mil. Desta forma, é interessante ressalvar que o relacionamento entre Brasil e Ásia até a década de 1950 ficou quase que unicamente restrito ao campo sociocultural representado pelo fluxo migratório japonês. Embora não tenham sido ainda realizados estudos aprofundados sobre o papel da colônia japonesa na capacidade de influência sobre o relacionamento nipo-brasileiro, a maior parte dos analistas procura apontar sua importância.

No começo dos anos 70, Roper discutia a presença de investimentos japoneses relacionados aos imigrantes afirmando: "It will be found that the proportion of Japanese investment in any country roughly correspond to the distribution of Japanese immigrants in Latin America" ${ }^{17} \mathrm{Na}$ mesma linha de raciocínio, Okita, no final dos anos 80, apontava: "Japanese interest in Latin America focuses on the region's economic development potential. However, because about 1 million Japanese live in Brazil, Japanese interest in this country is particularly strong. These Japanese immigrants have contributed greatly to Brazil's economic development". 18

Sem negar a relevância da existência da colônia, Horisaka, no entanto, pondera que a decisão tomada pelo MITI (Ministry of International Trade and Industry), na década de 1950, de investir no Brasil decorreu principalmente do potencial econômico e comercial que ele apresentava. ${ }^{19}$ Assim, nas décadas de 1950 a 1970, não se pode pensar propriamente num relacionamento Brasil-Ásia. Apesar de presente em discursos, principalmente a partir da política externa independente ${ }^{20}$ no governo Jânio Quadros, constata-se, na realidade, somente uma interação, no plano multilateral, de construção de uma agenda política comum a países em desenvolvimento no processo de defesa de instauração de uma nova ordem econômica internacional.

Nesse processo de construção de uma nova agenda política, o Brasil recebe a visita do presidente Sukarno, da Indonésia, em 59 - o primeiro presidente asiático a visitar o Brasil. E, em maio de 61, foi assinado um acordo bilateral econômico com aquele país. Excluindo estes dois eventos, pode-se afirmar

\footnotetext{
17 ROPER, P. Investment in Latin America. In: Economist Intelligence Unit. London, 1970. p. 10.

18 OKITA, Saburo. Japan's quiet strength. In: Foreign Policy. Washington, 1989. p. 141.

${ }^{19}$ Declaração em conversa informal com Kotaro Horisaka, em setembro de 1990. Veja também HORISAKA, Kotaro. A alvorada das relaçōes econômicas nipo-brasileiras. In: YOKOTA, Paulo. Fragmentos sobre as relaçôes nipo-brasileiras no pós-guerra (Org.). Rio de Janeiro: Topbooks. 1997. p. 55-78.

${ }^{20}$ A "política externa independente", implementada a partir do início dos anos 60 , corresponde à proposta de estabelecimento de uma política externa autônoma e voltada para a real promoção dos interesses brasileiros. Vai se caracterizar, por um lado, por uma tentativa de "universalização", ou seja, multiplicação de parcerias econômicas e políticas e, de outro, por uma maior aproximação com os países em desenvolvimento, visando uma ação coordenada e conjunta na defesa de interesses comuns.
} 
sobre a inexistência, até a década de 1980, de um relacionamento concreto entre os dois países, ou mesmo com o Sudeste Asiático. Na realidade, a Indonésia passa a compor o imaginário político no que se refere ao estreitamento de vínculos com o mundo afro-asiático, dentro dos pressupostos da política externa independente. A intensificação das relações com o mundo afro-asiático seria conseqüência da necessidade de autodeterminação não só nacional, mas também do contexto afro-asiático com vistas à superação mútua do subdesenvolvimento.

Dentro dessa perspectiva Cooperação Sul-Sul, a política externa brasileira nitidamente envolveu-se mais profundamente com o continente africano, desenvolvendo o que se chamou de política africana. Essa política claramente representou, enquanto emblema, o envolvimento brasileiro com as perspectivas de geração de uma nova ordem econômica internacional ou com sua política de Terceiro Mundo. Celso Lafer defende a tese de que "a política exterior independente procurou articular no sistema internacional uma frente única dos subdesenvolvidos com o objetivo de proteger os preços das matérias-primas e produtos agrícolas e forçar o sistema internacional a responder satisfatoriamente às demandas de industrialização". 21

Essa aproximação com o continente africano, interpretada como uma opção em relação à Ásia e, em especial, ao Sudeste Asiático que poderia oferecer vantajosas oportunidades comerciais, passou a sofrer no início dos anos 90 uma série de críticas. Gibson Barbosa, ministro de Relaçóes Exteriores de 69 a 73, pondera: (...) não houve opção naquela ocasião, como também não deve haver hoje, pois uma coisa não exclui a outra. De qualquer modo, o fato dominante no sudeste asiático, na primeira metade da década de 1970 , não eram os famosos 'tigres', tão louvados e invejados hoje, mas sim a guerra do Vietnã, que, como se sabe, terminou somente em 30 de abril de 75 . De tigre na região só havia na época os Estados Unidos da América, que, aliás, os chineses chamavam de 'tigre de papel'. Os chamados tigres asiáticos surgiram muito depois. ${ }^{22}$

Deve-se igualmente considerar que a política externa brasileira articulava o conceito de uma dupla inserção no cenário internacional. Uma, decorrente de seus laços históricos e tradicionais com o Ocidente e, outra, representada pela similaridade de deficiências que une o país a um conjunto de outros países que se situam numa posição de desvantagem dentro do sistema internacional. No entanto, essa perspectiva de dupla inserção não representa para a política externa brasileira a necessidade de opção entre alternativas diversas. Ao contrário, são movimentos percebidos como complementares e correspondentes a uma tentativa de diminuição da dependência em relação aos Estados Unidos.

${ }^{21}$ LAFER, Celso. Uma interpretação do sistema de relações internacionais do Brasil. In: Revista Brasileira de Política Internacional. ano X, n.39-40. Rio de Janeiro: IBRI, 1967. p. 99.

22 BARBOSA, Gibson. Depoimento em Funag. Reflexôes sobre a política externa brasileira. Brasília: Funag, 1993. p. 253. 
Há que se ressaltar também que o período inicial de universalização da política externa brasileira coincide, no plano internacional, com um momento no qual novas potências econômicas, em especial Alemanha e Japão, estavam buscando redefinir sua inserção, visando igualmente menor dependência dos Estados Unidos. E, nesse sentido, pressupōe-se que o posicionamento brasileiro no sistema internacional foi relativamente favorecido pela ampliação das disputas econômicas entre os países desenvolvidos.

Nesse período, o relacionamento brasileiro com a região asiática esteve basicamente restrito a suas relações com o Japão. Desde a década de 1960, as relações econômicas entre Brasil e Japão passaram por um incremento significativo, à medida que o Japão assumia o papel de segundo mercado individual para as exportações brasileiras e terceiro maior investidor externo no Brasil. No entanto, o estudo dessas relaçōes aponta para o fato de que seu incremento se deveu, primordialmente, a iniciativas por parte do Japão.

Nesta linha de raciocínio, deduz-se que as exportaçóes brasileiras para o Japão são, em sua maioria, determinadas claramente pelos investimentos japoneses no Brasil, os quais privilegiam a produção de insumos industriais vitais para a economia japonesa. Além disto, de forma menos significativa houve também uma realocação das chamadas sunset industries, cujos elevados gastos em energia, mão-de-obra e impacto ambiental não permitiam que a produção no Japão mantivesse competitividade elevada se localizadas em seu território.

"O que mais parece ter influído para a especialização nipônica em determinados setores da economia brasileira foi a meta de garantir insumos fundamentais para a sua indústria, conjugada à reestruturação industrial da economia japonesa, realocando no exterior setores intensivos em mão-de-obra, energia e altos custos ambientais". ${ }^{23}$

Denota-se, assim, certa complementaridade entre os dois países: fornecimento de matérias-primas em troca de investimentos e fornecimento de produtos industrializados. Sob o ponto de vista político, mantém-se igualmente a visualização da complementaridade ou de uma estratégia conjunta visando redução de dependências em relação aos Estados Unidos, ou mesmo, de perspectivas similares no que se refere a suas inserçôes no sistema internacional. Nesse sentido, a ampliação do relacionamento com o Japão atendia aos pressupostos básicos da política externa brasileira de redefinição de sua inserção no cenário internacional, em coerência com os princípios da política pragmática em vigência. ${ }^{24}$

${ }^{23}$ AMORIM, Wellington Dantas. Contraste e Contato: Aspectos do Relacionamento Econômico entre Brasil e Japão. Brasília: Dissertação de Mestrado, Universidade de Brasília, 1991. p. 193.

${ }^{24}$ OLIVEIRA, Henrique Altemani \& AMORIM, Wellington Dantas. O relacionamento Brasil-Japão. In: ALBUQUERQUE, José Augusto Guilhon (org.) Sessenta anos de politica externa brasileira (19301990). São Paulo: Annablume, vol. 3, 2000. p. 475-496. 
Esta complementaridade nipo-brasileira sofre, no entanto, um processo de retração a partir do início dos anos 80 , em decorrência, de uma parte, da diminuição da importância da garantia de fornecimento de matérias-primas, seja pelo aumento da oferta como pela queda dos preços reais e, de outra, pela aceleração da crise econômica brasileira, revertendo as expectativas de que a economia brasileira continuaria crescendo a ritmo acentuado. Não se pode deixar de considerar que o distanciamento decorre não só dos problemas brasileiros, mas também do novo posicionamento internacional que o Japão assume nos anos 80, em especial após a forte valorização do yen em 1985, com o Japão mais seguro quanto à sua dependência de acesso a determinadas matérias primas.

Esta crise inclusive propicia o surgimento do fenômeno chamado dekassegui, ou seja, o estabelecimento de um fluxo migratório de descendentes de japoneses para trabalho no Japão. Os dekasseguis, atualmente em torno de 250 mil, passaram a ser um fator importante no relacionamento nipo-brasileiro enquanto fonte significativa de fluxo de capitais. ${ }^{25}$

Mesmo com a reversão de expectativas com relação ao crescimento econômico brasileiro durante as décadas de 80 e 90, o investimento direto estrangeiro foi atraído na década de 1990 pelo amplo processo de privatização ocorrido no Brasil. Apesar de atrair novos investidores como os espanhóis e portugueses os asiáticos em geral se mantiveram fora desse processo de privatização. Independente desse processo, durante a mesma década cresceu a presença de empresas coreanas e chinesas no Brasil, como ilustram os casos, mencionados anteriormente, da Samsung, LG, Huawey e Shangai Baosteel.

Nos primeiros anos deste século, percebe-se também um crescente aumento do comércio bilateral brasileiro com os países asiáticos. As exportaçôes brasileiras para a China, mais por necessidades chinesas do que por um esforço exportador brasileiro, bateram recordes de crescimento. A presença de empresas chinesas em busca de parcerias estratégicas com empresas e governos locais, quer para participar do mercado local, quer para garantir o suprimento de produtos básicos, como os minérios e, marcadamente, a soja tem caracterizado o relacionamento do país com a Ásia. Será a China, neste novo século, o motor de um maior relacionamento do Brasil com a Ásia?

\section{Estudos asiáticos no Brasil do pós-Guerra à década de 1980}

Os estudos, no Brasil, referentes à região da Ásia-Pacífico encontram-se em estágio inicial, não se detectando programas ou instituiçôes consolidadas. Em seu desenvolvimento histórico, no início dos anos 60 e relativamente em consonância com a implementação da política externa independente podem

25 Para uma visão mais atualizada sobre a questão dos dekasseguis veja-se NINOMIYA, Masato \& TANAKA, Aurea Christine. Os Trabalhadores Brasileiros no Japão. In: AMARAL Jr., Alberto \& SANCHEZ, Michelle Ratton. Relações Sul-Sul: países da Ásia e o Brasil. São Paulo: Aduaneiras, 2004. p.: 277-316. 
ser apreendidas a partir do estabelecimento de centros de pesquisa de caráter mais abrangente, englobando o conjunto dos países não desenvolvidos ou, mais especificamente o que passaria a ser chamado de Terceiro Mundo. ${ }^{26}$

Assim, de uma forma genérica, estes centros de estudos englobam África, Ásia e Oriente Médio. ${ }^{27}$

Houve um desenvolvimento mais sistemático dos Estudos Africanos ${ }^{28}$, enquanto os Asiáticos terão início só no final dos anos 80 . O primeiro constituído foi o Centro de Estudos Afro-Orientais (Ceao) ${ }^{29}$, em 1959, e ligado à Universidade Federal da Bahia. É uma instituição voltada para o estudo, a pesquisa e ação comunitária na área de estudos afro-brasileiros e das ações afirmativas em favor das populações afro-descendentes, bem como na área dos estudos das línguas e civilizações africanas e asiáticas. Publica desde 65 a Revista Afro-Asia, de periodicidade semestral.

A denominação de estudos africanos ou asiáticos apresenta um sentido muito amplo, podendo se referir tanto aos estudos específicos sobre a Ásia, quanto sobre a comunidade asiática residente no Brasil ou ainda sobre as relaçōes entre o Brasil e a Ásia. No presente caso, o Ceao, apesar de apresentar os termos orientais e Ásia em sua publicação, está diretamente envolvido na análise das questôes que tratam a inserção dos afro-brasileiros na sociedade brasileira.

Outra iniciativa teve início quando Jânio Quadros assumiu a Presidência da República em 61. Seu governo conferiu um destaque especial aos países em desenvolvimento, enfatizando a possibilidade de instauração de uma maior aproximação não só política, mas também econômica, com vistas a uma complementaridade que reforçasse os esforços conjuntos para a superação do subdesenvolvimento. "O Brasil tem aumentado sua produção internamente em busca não apenas do mercado doméstico, mas, especificamente, na tentativa

\footnotetext{
${ }^{26}$ Não há mais dúvidas de que o “termo 'Terceiro Mundo' fora empregado pela primeira vez, em 1952, pelo demógrafo e historiador francês Alfred Sauvy num artigo publicado no periódico L'Observateur (14 de agosto de 1952) sob o título Trois Monde, Une Planète no qual 'no calor da Guerra Fria, (ele) usara para distinguir os países em desenvolvimento situados fora dos dois blocos de poder'. Mais tarde os colegas de Sauvy que trabalhavam no Institut National des Études Démographiques - relata Wolf-Philips - publicaram um trabalho intitulado Tiers Monde: sous developpement et developpement referindo-se ao termo numa analogia ao sentido de Tiers État retirado do discurso de Abbé Sieyes de 1789 que perguntava: 'o que é o Terceiro Estado? Tudo. O que tem sido até agora na ordem política? Nada. O que deseja ser? Alguma coisa'. Esse termo, no entanto ficara praticamente sem uso até os anos 70 e, no início dessa década a obra The New Language of Politics adicionava ao verbete Third Force a explicação de que '... Deveria ser utilizado Third World seguindo a expressão francesa, mas Third Force é empregado mais freqüentemente’”. (SATO, Eiiti. O papel dos países periféricos na ordem econômica internacional: percepções em mudança. São Paulo: Dissertação de Mestrado, Universidade de São Paulo, 1991. p. 15-16).

${ }^{27}$ Note-se que esta tendência não está circunscrita ao caso brasileiro. No México, em especial no El Colégio de México, também se observa a mesma tendência de agrupamento de estudos orientais com os estudos africanos.

28 Para uma análise mais aprofundada dos estudos africanos, veja-se: BELTRÁN. Luís. O Africanismo Brasileiro: incluindo uma bibliografia africanista brasileira (1940/1984). In: África, 8 bis, 1986. p.152.

${ }^{29}$ Para mais informações ver o site do Ceao: <www.ceao.ufba.br>.
} 
de atrair novos mercados: o interno, os da América Latina, África, Ásia e Oceania". ${ }^{30}$

Em um de seus primeiros bilhetes - pequenas anotações em pedaços de papel, característicos de sua forma autoritária de governar, Jânio solicitava providências ao Ministério das Relações Exteriores, Itamaraty, no sentido de: “a) constituir um grupo de trabalho com o objetivo de preparar a representação diplomática brasileira nos novos Estados africanos; b) elaborar esse ministério a política brasileira naquele continente, que deve ser reexaminada em todos os seus aspectos, sobretudo no político, no econômico e no cultural". ${ }^{31}$

Desta forma, criou-se o Instituto Brasileiro de Estudos Afro-Asiáticos (Ibeaa) pelo Decreto no. 54.465, de 14 de abril de 1961. De acordo com o Decreto no. 684-A que o regulamentou, seria um centro de altos estudos, destinado a estudar e a divulgar assuntos relacionados com os países da África e da Ásia e a colaborar com o Ministério das Relações Exteriores. Tinha como objetivos: a) estimular, desenvolver e difundir estudos culturais, sociais, políticos e econômicos relativos ao mundo afro-asiático; b) promover o estudo comparado dos processos de desenvolvimento do Brasil e dos países africanos e asiáticos, visando ao intercâmbio em benefício mútuo, da experiência de técnicas ou soluções adotadas; c) cooperar com o Ministério das Relações Exteriores no intercâmbio universitário entre o Brasil e os países africanos e asiáticos.

No entanto, em decorrência do golpe militar esse Instituto teve suas atividades encerradas em 1964. Posteriormente, o Centro de Estudos AfroAsiáticos (Ceaa), estabelecido e mantido pela Universidade Cândido Mendes, situada no Rio de Janeiro, incorpora seus antigos objetivos e pode ser considerado como o herdeiro do desaparecido Instituto Brasileiro de Estudos Afro-Asiáticos (Ibeaa) ${ }^{32}$. Suas atividades iniciaram-se em 1973 e compreendem estudos africanistas, orientais e afro-brasileiros, publicando desde 1978 a revista Estudos Afro-Asiáticos.

30 QUADROS, Jânio. A nova política externa brasileira. In: Relaçōes Internacionais. I, n.3, se/out 1978. p.76

31 RODRIGUES, José Honório. Brasil e África: outro horizonte. Rio de Janeiro: Nova Fronteira, 1982. p. 403.

32 Entende-se que o Ceaa é um herdeiro do Ibeaa pelo fato do Professor Cândido Mendes, proprietário da Sociedade Brasileira de Instrução/Universidade Cândido Mendes ter sido um dos pesquisadores do Ibeaa e ter praticamente mantido os mesmos objetivos institucionais. No momento da criação do Ibeaa, Cândido Mendes era ainda o Chefe do Gabinete Técnico da Presidência da República. No primeiro módulo do Seminário O Brasil e a Ásia no Século XXI: ao encontro de novos horizontes, em junho de 2001, Cândido Mendes apontava "eu me sinto muito feliz de estar aqui, em uma Casa que possui a mais antiga instituição de estudos sobre a Ásia, criada aqui, em Brasília, durante o Governo Jânio Quadros, no momento em que, pela primeira vez (eu chefiava a sua assessoria técnica), se pensou a partir de uma perspectiva terceiromundista, aquela que se desenhou mais tarde, nos governos que o sucederam, e que nos deu um eixo diferente, saindo daquelas boas agulhas magnéticas para o mundo clássico de nossa formação". ALMEIDA, Cândido Mendes. América Latina e Ásia: globalização, identidades e diferenças. In: FUJITA, Edmundo (org). O Brasil e a Ásia no Século XXI: ao encontro de novos horizontes. Brasília: IPRI, 2003. p.17 
Zamparoni aponta que o Ceaa apresentou três fases claramente diferenciadas, sendo a primeira fase mais direcionada para as questôes africanas relacionadas com os processos de libertação colonial dos "países de língua oficial portuguesa" (PALOP) e particularmente para a conjuntura política da África Austral e, num segundo momento, a tônica passou a ser o estudo sobre as relaçôes BrasilÁfrica, questōes de desenvolvimento e cooperação, já num quadro de pósindependência dos PALOP. E que, a partir da metade dos anos 1980, voltouse mais para estudos afro-brasileiros e particularmente para as questóes das relações raciais no Brasil. Zamparoni acrescenta ainda que o apoio financeiro da Fundação Ford foi determinante nesta mudança de prioridades, sendo hoje a principal atividade de produção acadêmica do Ceaa o seu Laboratório de Relações Raciais. ${ }^{33}$

Além destes, podem ser ainda citadas duas outras iniciativas nas décadas de 1960 e 1970, mas que praticamente não apresentaram desenvolvimento vigoroso. Uma delas, foi o Centro de Estudos Afro-Asiáticos de Natal, em 65, com o objetivo de especializar-se nos estudos africanistas e orientais, como também nas relações entre esses continentes e o Brasil. A outra, o Instituto Brasileiro de Cultura Luso-Afro-Asiática, fundado por iniciativa de portugueses e brasileiros no Rio de Janeiro em 1977, com a pretensão de se ocupar com os estudos da Ásia e de toda a área de fala portuguesa em função da cultura lusitana. ${ }^{34}$

Neste período, merece destaque ainda o desenvolvimento de alguns cursos regulares de ensino do idioma japonês e localizados normalmente em universidades públicas, como a Universidade de São Paulo (USP), onde existe também a Casa da Cultura do Japão para estudos e eventos de caráter cultural ${ }^{35}$, a Universidade Federal do Estado do Rio de Janeiro (UFRJ), a Universidade Federal do Estado do Rio Grande do Sul (UFRGS), a Universidade Estadual Paulista (UNESP) e a Universidade de Brasília (UnB). Cursos de extensão passaram a ser igualmente oferecidos na Universidade Estadual de Campinas (UNICAMP), Universidade Estadual de Maringá (UEM) em seu Instituto de Estudos Japoneses, Universidade Estadual de Londrina (UEL), Universidade Federal do Estado do Paraná (UFPR), Universidade Federal do Estado da Bahia (UFBA), Universidade Estadual da Bahia (UNEB), entre outros.

$\mathrm{Na}$ década de 1960, constata-se ainda uma experiência pioneira que poderia ter dado origem ao desenvolvimento da área de estudos regionais no

\footnotetext{
33 ZAMPARONI, Valdemir. Os estudos africanos no Brasil. Disponível em: <www.historianet.com.br>. Acessado em 08 de junho de 2005.

34 Vale a pena ainda registrar a criação do Centro de Estudos Africanos da Universidade de São Paulo, em 1963 , sendo, no período, o único que assumia a sua vocação africanista.

35 Em 1968 foi criado o Centro de Estudos Japoneses da Universidade de São Paulo (CEJ-USP) com o objetivo de formar pesquisadores em áreas como Língua, Literatura e Cultura Japonesa e, em 1996, implantou o Curso de Pós-Graduação em Língua, Literatura e Cultura Japonesa.
} 
país. Com base na manutenção de cursos livres de idiomas (russo, hebraico e árabe) implantados nos anos 40, o Departamento de História, da antiga Faculdade de Filosofia, Ciências e Letras da Universidade de São Paulo criou a seção de Estudos Orientais, dando início aos cursos de bacharelado das áreas de árabe, armênio, hebraico, japonês e russo. Em 1968 agregam-se a esta Seção as áreas de chinês e sânscrito. O objetivo era o de especialização por área, com o estudo não só de língua e cultura, mas também de história, política (nacional e internacional), sociedade e economia.

No entanto, a partir da reforma universitária de 70, a antiga Seção de Estudos Orientais passou ao âmbito do Curso de Letras, com a criação do Departamento de Lingüística e Línguas Orientais. Com o desmembramento de Lingüística, em 1986, passou a chamar-se Departamento de Línguas Orientais e, posteriormente, Departamento de Letras Orientais. ${ }^{36}$ Desde a reforma universitária, que fundamentalmente extinguiu as cátedras e organizou as diversas áreas do conhecimento em departamentos, não existiu outra iniciativa de estudos asiáticos no Brasil que não estivesse atrelada ao estudo de idiomas e, na melhor das hipóteses, cursos esporádicos sobre aspectos culturais dos povos asiáticos.

\section{Renovado esforço dos estudos asiáticos no Brasil a partir da década de 1980}

Considerando a Ásia como um todo, é necessário ponderar que, dos anos 80 até hoje, tem havido um relativo aumento do interesse da sociedade em geral, dos empresários e dos acadêmicos por aquela região. Inicialmente, ainda na década de 1980, o Japão que comprava o Rockfeller Center, a Columbia Pictures, a CBS Records, entre outras empresas norte-americanas, e que se apresentava como a principal economia mundial atraía a atenção dos analistas econômicos e dos que desejavam aprender e emular seu modelo de administração de empresas e desenvolvimento econômico. Aos poucos, porém, começou a se fazer presente a percepção de que a economia asiática não representava somente o Japão, mas também o Sudeste Asiático e igualmente a República da Coréia. Por fim e, em especial, a partir da metade da década de 1990, começava igualmente a ser objeto de interesse o entendimento de como a República Popular da China conseguia firmar-se como uma economia emergente e provável potência do século XXI.

Desta forma, é a partir do final da década de 1980 que começam a ser observados os primeiros movimentos de se tentar estruturar um processo de estudos sobre a Ásia em si e sobre as relaçōes entre Brasil e Ásia. De qualquer forma, este momento é caracterizado pelo surgimento de iniciativas individuais

36 Para informações sobre as atividades de ensino, pesquisa e extensão deste departamento da Universidade de São Paulo, acessar o site: <www.fflch.usp.br/dlo>. 
e, na maioria, associado a projetos de mestrado e/ou doutorado, como, por exemplo, Ernani Teixeira Torres na UFRJ; Gilson Schwartz na UNICAMP, Wellington Dantas Amorim na UnB, Silvio Miyazaki e Alberto Sugo na EAESPFGV, entre outros. De outro lado, o ex-embaixador Amaury Porto de Oliveira amplia a sua participação acadêmica retomando suas análises iniciadas com as Cartas de Cingapura. ${ }^{37}$

No Centro de Estudos Afro-Asiáticos da Cândido Mendes, tem prosseguimento o trabalho abnegado de Severino Cabral no esforço de ampliação do conhecimento sobre a realidade chinesa. $\mathrm{Na}$ Universidade de Brasília, sob coordenação de Henrique Altemani de Oliveira, constituiu-se um Grupo de Estudos sobre as Relações Brasil-Japão, com financiamento da Fundação Ford. E, de certa forma com melhor infra-estrutura e recursos assegurados e contínuos, constitui-se, na Escola de Economia da Fundação Getúlio Vargas do Rio de Janeiro, em 1989, o Centro de Estudos Japoneses com recursos da Sasakawa Peace Foundation do Japão.

Com o objetivo de maximizar os esforços individuais e evitar dispersão de iniciativas e recursos, constituiu-se em 1991 a Sociedade Brasileira de Estudos sobre o Japão e o Pacífico (SBEJP). Conforme declara Gilson Schwartz, primeiro presidente da SBEJP, além da falta de um foro, um espaço, onde se pudesse desenvolver discussões e estudos acadêmicos: “(...) havia um interesse muito grande por um espaço novo que trouxesse o Japão acadêmico, mais próximo, e que fosse também um espaço de integração com os problemas da realidade brasileira, com os interesses, as dificuldades, e os desafios da sociedade brasileira. Esse foi o diagnóstico do qual o grupo partiu: de um lado, uma carência nas instituiçôes que trabalhavam com a questão japonesa; e de outro, (...) um interesse geral de se criar uma ponte entre estes dois mundos - Brasil e Japão. 38

Ainda que o nome da nova associação indicasse, além do Japão, o Pacífico, e tivesse se esforçado, nos cinco congressos que organizou, para a presença de temas que abordassem outros países da região, não se pode negar que, naqueles anos, a preocupação dos pesquisadores brasileiros estava prioritariamente direcionada ao estudo do Japão, com interesse residual para outros países da região. A SBEJP, por absoluta falta de recursos, teve que descontinuar suas

\footnotetext{
37 Não se pode deixar de observar o papel solitário e fundamental desempenhado pelo embaixador Amaury Porto de Oliveira na divulgação e no incentivo para o estudo sobre a região da Ásia Pacífico. Quando ainda na ativa e ocupando a embaixada brasileira em Cingapura, Amaury Porto iniciou um trabalho sistemático de reflexão sobre o processo asiático de desenvolvimento, com ênfase na perspectiva da Terceira Revolução Industrial. Suas reflexões foram publicadas pelo Instituto de Pesquisa de Relações Internacionais do Ministério das Relaçōes Exteriores (IPRI-MRE) sob a denominação de "Cartas de Cingapura". Após seu desligamento do ministério, Amaury Porto foi Pesquisador Associado do Instituto de Estudos Avançados da Universidade de São Paulo e, atualmente, é membro do Grupo de Análises da Conjuntura Internacional da Universidade de São Paulo (GACINT/USP).

38 SCHWARTZ, Gilson. Perspectivas das relações Brasil-Japão. In: NINOMIYA, Masato (org.). $O$ desenvolvimento das relações Brasil-Japão à luz da expansão econômica da região Ásia-Pacífico. São Paulo: Kaleidos-Primus, 1996. p. 63.
} 
atividades, mas mesmo assim, em 1998, alterou sua denominação para Sociedade Brasileira de Estudos sobre a Ásia e o Pacífico, após ter recepcionado a visita de uma missão da Academia de Ciências Sociais da República Popular da China.

Como apontado anteriormente, na década de 1990, em decorrência do fim da Guerra Fria e início do processo de reestruturação internacional visando uma redefinição do sistema internacional, bem como das regras que possam configurar um novo padrão de relacionamento internacional, o Brasil apresentou alguns ajustes em suas estratégias de inserção internacional. Dentre estas estratégias, a Ásia do Leste passou a ser vista como uma área de expressão no processo de inserção internacional brasileira, com conteúdo tanto econômico quanto político.

O interesse não é só do lado brasileiro, mas também do asiático que até então contava com o acelerado desenvolvimento econômico japonês e demais economias em rápido processo de industrialização, tendo a Coréia do Sul, por exemplo, ultrapassado o Brasil em termos de renda per capita no início dos anos 80. Inicialmente, a Ásia, seja em decorrência do processo de reestruturação do sistema comercial internacional, seja do crescimento da tendência de formações regionais econômicas, passou a encarar o Brasil como um possível parceiro tanto para o fornecimento de matérias-primas ou produtos alimentícios, quanto para recepção de produtos manufaturados ou para a instalação de unidades produtivas visando o mercado regional e continental.

A partir de 1995, esse processo se tornou importante pelo receio asiático de que as discussões para a implantação da Área de Livre Comércio das Américas possam dificultar ainda mais o acesso asiático aos mercados americanos. Esta preocupação, por exemplo, está bem expressa na análise do Ministério das Relações Exteriores do Japão quando reconhece: "há o perigo de que devido ao progresso na integração econômica da América Latina e do Caribe, as companhias japonesas possam ficar em desvantagem, através da região, na competição com as companhias dos Estados Unidos e da Europa".39

O embaixador do Japão no Brasil, Katsunari Suzuki, retrata muito claramente, de um lado, o atraso brasileiro no processo de ampliação de conhecimento sobre a Ásia e, de outro, a importância política e estratégica deste conhecimento: "Para o Brasil tornar-se, futuramente, um verdadeiro global player, acho imprescindível incorporar a Ásia dentro de sua esfera de atuação. Falando com toda franqueza, porém, o Brasil ainda não conta com um conhecimento profundo, em sua verdadeira acepção, sobre a Ásia. Daqui para o futuro, quando o Brasil ou a América do Sul tentar fortalecer seus laços com a Ásia, deve haver muitos pontos nos quais o Japão poderá atuar como um honest broker em prol do interesse de ambas as partes. Sendo assim, o Brasil e

39 JAPAN. Diplomatic bluebook 2004. Tokyo: Ministry of Foreign Affairs, 2004. p. 88. 
o Japão poderão fazer juntos muitas coisas, no sentido de os dois países se unirem para estabelecer o elo entre a América do Sul e a Ásia. E, numa perspectiva em longo prazo, o fato de o Brasil fortalecer sua relação com a Ásia e assim tornar-se um país com um relacionamento equilibrado com os Estados Unidos, Europa e Ásia, poderá ser de interesse do próprio Japão. ${ }^{40}$

De alguma maneira as preocupaçōes expressas pelo governo japonês nos documentos mencionados, estavam presentes quando da instalação, em 1986, da Associação Latino-Americana de Estudos Afro-Asiáticos do Brasil (Aladaab) como a Seção Nacional da Associação Latino-Americana de Estudos AfroAsiáticos (Aladaa). Foi estabelecida no Colégio de México, na cidade do México, com o objetivo de promoção de atividades e eventos na área de estudos afroasiáticos, vinculando e entrelaçando os esforços acadêmicos nesta área de conhecimento.

Tradicionalmente, no Brasil, seus congressos nacionais reúnem pesquisadores de quatro áreas distintas: estudos afro-brasileiros, estudos africanos, literatura africana e estudos asiáticos. No entanto, a presença de pesquisadores sobre Ásia, apesar do aumento do interesse brasileiro pela Ásia, é ainda residual. No livro que publicou as apresentaçôes do VI Congresso da Aladaab em 96, constam sete artigos sobre estudos afro-brasileiros, nove sobre estudos africanos, quatro sobre literatura africana e quatro em estudos asiáticos. ${ }^{41}$ Nestes últimos, além da baixa presença de análises sobre a Ásia, os temas são ainda extremamente desconexos, impossibilitando uma reflexão conjunta, sendo um artigo sobre política externa chinesa, um sobre teatro indiano clássico, outro sobre a noção de pessoa em Keiji Nishitami e o quarto sobre a colonização portuguesa na Índia.

Da mesma forma, no VII Congresso, realizado em novembro de 2004 em Brasília, foram apresentados 66 trabalhos, sendo 25 sobre estudos africanos, 19 sobre estudos afro-brasileiros, nove sobre literatura africana, sete de estudos asiáticos e três sobre relações brasileiras com países do Sul e três sobre outros temas. Este último quadro reflete de uma forma muito clara e crua o fato de que a área de estudos asiáticos no Brasil ainda carece de um esforço muito forte no sentido de minimamente poder se estruturar para produzir um conhecimento mais sistemático sobre a realidade asiática, de um lado, e sobre o relacionamento brasileiro com a Ásia, de outro. ${ }^{42}$

Mesmo assim, pode-se considerar um relativo avanço na área a constituição de alguns grupos com ênfase específica na Ásia. A Universidade Cândido

\footnotetext{
40 BRASIL. Simpósio Internacional de Pesquisas Econômicas Brasil-Japão. São Paulo: Universidade de São Paulo, 2001. p. 11 .

41 DÖPCKE, Wolfgang. Crises e reconstruções: estudos afro-brasileiros, africanos e asiáticos. Brasília: Linha Editorial, 1998.

42 A pouca produção sobre Ásia pode ser percebida também pela reduzida frequêencia de Congressos. Após a realização de 5 encontros a cada 2 anos. O período foi dilatado para um congresso a cada 8 anos.
} 
Mendes, no Rio de Janeiro, manteve o Ceaa voltado para os estudos africanos enquanto os Estudos Afro-Brasileiros passaram a estar compreendidos no recente Centro de Estudos Afro-Brasileiros (Ceab). Já os estudos asiáticos, praticamente reduzidos à análise sobre a China e sobre o relacionamento sino-brasileiro ficaram alocados dentro do Centro de Estudos das Américas daquela universidade.

$\mathrm{Na}$ Universidade de Brasília, foi criado, em 1987, o Neásia - Núcleo de Estudos Asiáticos, desenvolvendo atividades multidisciplinares sobre a Ásia e o Pacífico Asiático assim como sobre as relações do Brasil com os países asiáticos. ${ }^{43}$ A criação de um curso de bacharelado em língua e literatura japonesa, em 1997, na Universidade de Brasília indiretamente contribuiu para reforçar a consolidação do Neásia, em primeiro com a atuação de Ronan Alves Pereira e, atualmente, com Lytton Guimarães. O Neásia, em razão da proximidade com as representações diplomáticas dos países asiáticos em Brasília e da relativa vinculação com estudantes e pesquisadores do curso de Relaçóes Internacionais da Universidade de Brasília, apresenta uma vocação para uma especialização em torno de análise de questōes internacionais da região da Ásia-Pacífico.

$\mathrm{Na}$ Universidade de São Paulo, o Núcleo de Pesquisa em Relações Internacionais ${ }^{44}$ abriu uma linha de pesquisa específica sobre a Ásia a partir de 1995, com Alexandre Uehara trabalhando mais sobre o Japão, Henrique Altemani sobre a China e Gilmar Masiero sobre a República da Coréia. Desde então, Uehara desenvolveu sua tese de doutorado sobre a política externa japonesa ${ }^{45}$ e tem publicado vários artigos em jornais e revistas como também liderado discussōes acadêmicas junto à Fundação Japão. Gilmar Masiero segue investigando o desenvolvimento econômico asiático e da mesma forma Henrique Altemani, lidera na Pontifícia Universidade Católica de São Paulo a formação do Grupo de Estudos Ásia-Pacífico ${ }^{46}$, trabalhando principalmente sobre os temas de segurança regional, integração e políticas externas dos países do Leste Asiático.

Ainda na Universidade de São Paulo, Alexander Chung Yuan Yang, imbuído do ideal que tinha norteado a criação dos cursos de Estudos Orientais, promoveu em setembro de 1995 o I Congresso Nacional de Docentes e Pesquisadores Chineses e Sinólogos do Brasil com o intuito de incentivar a criação de um Centro de Estudos Chineses. Ainda que formalmente este centro não tenha sido constituído, o grupo de professores do curso de língua chinesa na USP continua promovendo seminários e publica a Revista China em Estudo.

\footnotetext{
43 Informações através do site: <www.unb.br/ceam/neasia>.

44 Informações através do site: <www.usp.br/relint>.

45 A tese de doutorado de Alexandre Uehara foi publicada sob o título: A política externa do Japão no final do século XX: o que faltou? São Paulo: Annablume, Fundação Japão, 2003. 268 p.

46 Informaçôes através do site: <www.asiapacifico.com>. Veja-se também a newsletter: Ásia em Foco. Disponível em: <www.asiaemfoco.com>
} 
$\mathrm{Na}$ Universidade Federal do Rio Grande do Sul, o Núcleo de Estratégia e Relações Internacionais (Nerint), sob a coordenação de Paulo Vizentini começou também a apoiar o desenvolvimento de reflexões sobre o contexto asiático, por meio de uma linha de pesquisa específica voltada para a análise da realidade estratégica, a inserção internacional e o desenvolvimento econômico que vem ocorrendo na Ásia-Pacífico. ${ }^{47}$ E, em abril de 2002, foi estabelecida a Associação Brasileira de Estudos Japoneses (Abej) que visa congregar professores, pesquisadores e estudantes de Estudos Japoneses, na acepção mais geral do termo, bem como aqueles que desenvolvem trabalhos relacionados com a cultura japonesa. Seus objetivos são o de incentivar o ensino, a pesquisa acadêmica e a pesquisa-ação, bem como promover a divulgação e o intercâmbio de produção didática e científica em Estudos Japoneses, apoiar a criação e a melhoria de cursos de língua e cultura japonesa, incrementar a troca de informações e contatos profissionais com outras associações de ensino e pesquisa, nacionais e internacionais. ${ }^{48}$

A Fundação Japão, com sede em São Paulo, tem, de forma sistemática, acompanhado a situação dos estudos japoneses no país, com a elaboração de um diretório de pesquisadores e instituições de pesquisa. Devido à defasagem dos dados (os levantamentos anteriores foram realizados em 84 e 88, sendo que o diretório atual é resultado da pesquisa realizada em 98) está sendo realizada uma nova versão. A Universidade do Estado do Rio de Janeiro (Uerj), com a abertura oficial de sua cátedra no ensino da língua japonesa a partir de 2003, junto com a sua equipe de professores da área de ciências sociais e humanas, foi escolhida para realizar o levantamento nacional, que está em vias de finalização. Nele, percebe-se uma nítida tendência de mudança de enfoque, anteriormente com forte presença da área de língua, em direção à diversificação de assuntos. ${ }^{49}$

Cabe ainda apontar o surgimento de entidades não diretamente voltadas para estudos asiáticos, mas que desempenham um papel fundamental enquanto apresentam o objetivo, entre outros, de colaborar para o estreitamento das relaçōes bilaterais. Detecta-se assim a importância tanto da Associação BrasilJapão de Pesquisadores, anteriormente sob a denominação de Sociedade Brasileira de Pesquisadores Nikkeis, quanto da Associação Brasileira dos Professores Universitários Coreanos, sob liderança do professor Hee Moon Jo.

Ainda que não estejam arroladas todas as iniciativas, todos os pesquisadores e grupos que direta ou indiretamente estejam trabalhando com o tema de estudos asiáticos, a presente e breve descrição evidencia o reconhecimento de que os estudos asiáticos no Brasil apresentam uma relativa mudança, a partir

\footnotetext{
47 Informaçōes disponíveis em: <www.ilea.ufrgs.br/nerint>.

48 Informaçôes disponíveis em: <www.ahcaiafa.com.sites/abej/principal/index.php>

49 Os dados do último levantamento (1998) estão disponíveis em FUNDAÇÃO JAPÃO. Estudos Japoneses no Brasil. São Paulo: Fundação Japão, 1998. p. 132 (Pesquisa, 9). Os dados estão igualmente disponíveis em: <www.fjsp.org.br>.
} 
dos anos 90. Esta mudança se caracteriza pela agregação de interesses mais diversos, até então concentrados no Japão. Na eleição de novos temas ou novos países, a China, principalmente nos últimos anos, passou a representar o país que mais está atraindo a atenção de estudiosos ou de trabalhos acadêmicos. ${ }^{50}$ A República da Coréia, por sua capacidade econômica, sua rapidez na redução dos efeitos da crise asiática, seu desenvolvimento tecnológico, entre outros fatores, está igualmente atraindo interesses, mas sem que, até o momento, tenha sido estruturado um esforço mais sistematizado de análise por pesquisadores brasileiros. ${ }^{51}$ Esperanças, entretanto, recaem sobre o acordo de cooperação firmado em março de 2005, entre a Universidade de São Paulo e The Korea Foundation. Com vigência de cinco anos, o acordo envolve cooperação acadêmica em Estudos Coreanos, nas áreas de Língua Coreana, Estudos Comparativos e Relações Internacionais.

Pelo acordo de cooperação, a Universidade de São Paulo, além de envidar esforços para patrocinar intercâmbios de alunos e pesquisadores, se obriga a estabelecer e co-patrocinar um curso permanente de língua coreana, organizar anualmente uma Semana de Estudos Coreanos e uma Conferência sobre Brasil e Coréia: Comparativo e Perspectivas. Por seu lado, The Korea Foundation também providenciará bolsas de estudo e pesquisas, co-patrocinará o emprego de instrutores dos cursos de língua e seminários e conferências sobre estudos coreanos e estudos comparativos Brasil-Coréia.

O Instituto de Pesquisa de Relações Internacionais do Ministério das Relações Exteriores (Ipri-MRE), com a preocupação de buscar um conhecimento

\footnotetext{
50 A titulo de exemplo pode-se mencionar os artigos de Amaury Porto de Oliveira, O salto qualitativo de uma economia continental e Dissonâncias e convergências sino-japonesas no século XXI publicados respectivamente na revista Politica Externa. Vol 11 n.4, 2003. p.5-11. e vol. 12, n.4, 2004. p.7-2 ou ainda o trabalho de Henrique Altemani de Oliveira, Brasil-China: trinta anos de uma parceria estratégica publicado na Revista Brasileira de Politica Internacional, ano 47, n.1, 2004. p.7-30 e o texto de Gilmar Masiero, Administração e crescimento econômico: a experiência das township and village enterprises (TVEs) chinesas merecedor do Prêmio Belmiro Siqueira de Administração em 2004 e publicado na Revista Brasileira de Administração ano XV, n.48, mar 2005.p. 43-55.

51 Apesar da pouca especialização em assuntos coreanos nas instituiçōes brasileiras já é significativo o número de dissertações e teses desenvolvidas em programas de pós-graduação. Entre os trabalhos mais citados, desenvolvidos a partir de 1990, encontram-se: CHOI, K.J. Além do arco-iris: a imigração coreana no Brasil. São Paulo: Dissertação de Mestrado, Universidade de São Paulo, 1991; CANUTO, Otaviano. Processos de industrialização tardia: o paradigma da Coréia do Sul. Capinas: Tese de Doutorado, Universidade Estadual de Campinas. 1991.

SANG, K. Socialização de jovens imigrantes coreanos. São Paulo: Dissertação de Mestrado, Universidade de São Paulo, 1993; LEE, Sangki. Brasil e Coréia do Sul: Aspectos politico-econômicos do relacionamento bilateral. Brasília: Mestrado em Relaçôes Internacionais, Universidade de Brasília, 1995; CHOI, K.J. Aspectos fonético-fonológicos do português falado por coreanos. São Paulo: Tese de Doutorado, Universidade de São Paulo, 1996; WOO, Young-Sun. O relacionamento Brasil-Coréia no período de 1988-2001. Brasília: Mestrado em Relaçôes Internacionais, Universidade de Brasília, 2002; MEE JOUNG, L. Evolução global da indústria da TI (Tecnologia da Informação): uma abordagem comparativa do Brasil e da Coréia do Sul. São Paulo: Tese de doutorado, Universidade de São Paulo. 2004; DOO-BIN, I. A aquisição do tempo composto do português como LE e L2 por Coreanos. Araraquara: Tese de Doutorado, Universidade Estadual Paulista, 2004.
} 
maior sobre países de especial importância para o Brasil e assim contribuir para a gradual construção de uma visão brasileira sobre as principais sociedades e Estados passou no final da década de 1990 a promover uma série de seminários. Com relação aos países asiáticos, considerados neste trabalho, realizou o seminário "Brasil-China" em novembro de 1999, "Coréia" em outubro de 2000 e "Japão" em dezembro de 2000. E, juntamente com o Departamento da Ásia e Oceania do Ministério das Relações Exteriores, patrocinou, em junho de 2001, o seminário "O Brasil e a Ásia no século XXI: ao encontro de novos horizontes". 52

O aumento das visitas presidenciais quer das lideranças asiáticas ao Brasil, quer do presidente ou de outras autoridades brasileiras aos países asiáticos, nos anos recentes, tem estimulado a realização de seminários e encontros em várias esferas do governo. ${ }^{53}$ Infelizmente essas atividades são pontuais e carecem de maior esforço de sistematização e divulgação dos resultados. Além dos centros acadêmicos anteriormente mencionados, timidamente, na maioria dos casos por escassez de recursos, surgem outras iniciativas no interior das instituições de ensino superior brasileiras, principalmente atreladas aos emergentes cursos de Relações Internacionais. Exemplo nesta direção é o Grupo de Estudos da Ásia-Pacífico da PUC/SP, estabelecido em 2004. Em sua curta trajetória de existência já realizou três encontros denominados de "Semana de Estudos Asiáticos". Após encontros sobre o Japão e China realizou, um seminário específico sobre a República da Coréia, em abril de 2005.

\section{Comentários finais}

Aparentemente, qualquer tipo de conclusão que se faça tem que apontar o que está por demais patente: a área de estudos asiáticos no Brasil é recente, com um número exíguo de instituições e de pesquisadores, com carência de recursos e estando, até recentemente, quase que integralmente concentrada em estudos direcionados ao Japão.

No entanto, dado o atual interesse econômico e político que o Brasil demonstra pelo continente asiático ("Se temos uma vocação regional, somos, também um país global. Da mesma forma que a integração nacional passa pela integração regional, estou convencido de que a aproximação com a Ásia e, em particular com a China, será decisiva para o Brasil realizar esse destino

\footnotetext{
52 Os textos dos seminários relativos ao Japão e à China ainda estão em fase de edição, enquanto que os sobre a Coréia já foram publicados (GUIMARÃES, Samuel Pinheiro (org.). Coréia: visōes brasileiras. Brasília: IPRI, 2002), assim como os do seminário com o Departamento da Ásia e Oceania (FUJITA, Edmundo (org). O Brasil e a Ásia no Século XXI: ao encontro de novos horizontes. Brasília: IPRI, 2003). 53 No atual governo do Presidente Luís Inácio Lula da Silva, o Brasil recebeu a visita do primeiro ministro do Japão, dos presidentes da China e da Coréia do Sul, tendo o presidente brasileiro visitado igualmente os três Estados.
} 
maior" $)^{54}$, torna-se cada vez mais premente a necessidade de se buscar um entendimento melhor de uma região até então negligenciada nas preocupaçóes dos analistas e estudiosos brasileiros.

Assim, em primeiro lugar, pode-se observar uma presença européia muito forte no cotidiano brasileiro, reforçando este distanciamento e desconhecimento do continente asiático. Independentemente de algumas características brasileiras decantadas, como o pluralismo étnico e a importância atribuída a outras regiōes, o Brasil permanece culturalmente influenciado e direcionado para a Europa e para os Estados Unidos. Aparentemente esta observação aplica-se também aos fluxos comerciais com uma relativa inércia para estas duas áreas, enquanto que a diversificação para outras é normalmente reflexo de uma forte ação governamental. Há assim, uma total marginalização da Ásia na educação brasileira, em todos os níveis, negligenciando-se, tanto no ciclo básico, quanto no secundário e mesmo no universitário, o conhecimento da região asiática e mesmo da africana. Esta observação reforça a perspectiva do caráter eurocêntrico da sociedade brasileira.

Em segundo lugar, e em parte decorrente da primeira observação, detectase uma contínua e persistente falta de política de apoio material à consolidação de instituiçôes voltadas a suprir esta deficiência. Se, tradicionalmente, já há uma relativa falta de apoio às próprias universidades, não é difícil imaginar a dificuldade de obtenção de fundos para a criação ou manutenção de Centros de Estudos Asiáticos.

De outro lado, constata-se, da mesma forma, ausência de cultura de financiamento privado para estudos das mais variadas áreas. Há um relativo entendimento de que a manutenção de centros de estudos é um custo que deve ser mantido pelo Estado, sendo que o setor privado só aplica em atividades que aparentemente possibilitem um retorno imediato. No caso dos estudos japoneses, observa-se uma relativa exceção, mas que decorre de entidades relacionadas com o Japão, como a Fundação Japão, o Banco América do Sul, e a Sasakawa Peace Foundation. Por isto mesmo que a Fundação Ford em especial, mas também as Fundações Alemãs (Konrad Adenauer e Friedrich Ebert) desempenham um papel fundamental no desenvolvimento das Ciências Sociais no país. 55

\footnotetext{
54 Discurso do presidente da República, Luiz Inácio Lula da Silva, na solenidade de Abertura do Seminário Brasil - China: "Um Salto Necessário" - BNDES - Rio de Janeiro, 30 de abril de 2003. In: Palavra Internacional do Brasil. 2 de maio de 2003. Disponível em: <http://www.relnet.com.br>.

55 A Fundação Ford teve um papel fundamental no financiamento das atividades do Centro de Estudos Afro-Asiáticos da Universidade Cândido Mendes, financiou o Projeto de Relações Brasil-Japão desenvolvido na Universidade de Brasília no final dos anos 80 e início da década de noventa (dentro do projeto maior de apoio ao desenvolvimento da área de Relações Internacionais no país). Atualmente está fortemente incentivando estudos sobre o G3 (Índia, Brasil e África do Sul). Cabe ainda mencionar a presença da Fundação Sasakawa desde 1993, na Universidade de São Paulo, financiando estudos de pós-graduação voltados preferencialmente à área de Relações Internacionais.
} 
E, sem dúvidas, associada a esta questão de falta de recursos, a especialização acadêmica pela área de estudos asiáticos implica perda de oportunidades profissionais pelo fato de não haver praticamente, nos diferentes cursos universitários, uma grade curricular que propicie oportunidades de aplicação destes conhecimentos e, porque não, de contratação. No caso brasileiro, esta possibilidade de especialização é grave pelo fato da não existência da carreira de pesquisador. Sendo assim, o pesquisador tem que ser, em primeiro, professor, sendo que seu envolvimento em pesquisas é sempre por interesse próprio ou complementar à carreira de professor.

Finalmente, como decorrência de um círculo vicioso, constata-se fraca organização cooperativa. Não há centros de estudos, em parte pelas razões acima enumeradas, e esta ausência impede a formatação de associações que pudessem operar na consolidação da área. Neste caso, o exemplo da Sociedade Brasileira de Estudos sobre a Ásia e o Pacífico é bem ilustrativo. Surgiu por iniciativas individuais e, por falta de recursos, permanece no papel, mas sem qualquer tipo de atividade. É igualmente ilustrativa a institucionalização da Associação Brasileira de Estudos Japoneses em 2002. Ainda que compreenda estudos sobre um país com o qual o Brasil mantém um intenso relacionamento econômico e comercial desde o final dos anos 50, com a presença de projetos de ensino de língua e cultura desde os anos 60, com uma comunidade comparativamente ampla e com relativa influência política e com apoio de uma das poucas instituições atuantes no país (Fundação Japão), só recentemente reuniu condições de buscar uma política de consolidação da área de estudos japoneses no país. ${ }^{56}$

Entretanto, há uma questão que sobremaneira reforça este distanciamento, desconhecimento da Ásia. O que a Ásia, e aí podemos pensar diretamente em cada país compreendido neste universo chamado de Ásia, conhece do Brasil? Nada! Ou, da mesma forma como se processa no Brasil, há um trabalho franciscano de poucos pesquisadores isolados, ou ainda que mais raro, de poucas instituições voltadas a pensar o Brasil e suas relaçôes com a Ásia.

Talvez a única possibilidade de superação deste atraso de conhecimentos e informações seja o desenvolvimento de vontades políticas que propiciem ações concretas. Por parte dos governos, direcionando recursos para a implementação de intercâmbios de professores/pesquisadores que se dediquem ao ensino de língua e cultura, ou de pesquisadores asiáticos em Centros de Estudos no Brasil e de pesquisadores brasileiros em Centros de Estudos na Ásia, bem como para a manutenção de instituições no país, com recursos para infra-estrutura e acesso a materiais de estudo (livros, periódicos, viagens e

${ }^{56}$ Estas observaçōes, em parte foram inspiradas pela análise de: PEREIRA, Ronan Alves. Japanese studies in the west: Brazil today (Part 2). In: Tsushin - Edwin O. Reischauer Institute of Japanese Studies. vol., n.2, fall 1999. p. 2-4. 
realização de eventos acadêmicos). Por parte das universidades, disponibilizando recursos para a instalação e atuação desta área de estudos e remuneração dos pesquisadores. E, por parte de Fundações e empresas privadas diretamente interessadas na ampliação das relações bilaterais.

Recebido em 16 de setembro de 2005 Aprovado em 15 de outubro de 2005

\section{Resumo}

A análise das relações Brasil e Ásia constata a existência de certos esforços para um relacionamento mais consistente e abrangente entre ambos, seja no âmbito político, econômico e acadêmico. Entretanto, a taxa de intercâmbio entre eles ainda permanece muito aquém do desejável. Assim, discute-se perspectivas e possibilidades de crescimento de tal relacionamento entre os dois, como forma de fazer valer as iniciativas já correntes.

\section{Abstract}

The analysis of the relations Brazil-Asia shows the existence of certain efforts towards a relationship more consistent and wider among both, politically, economically and academically. However, the exchange rate among them is still way below the desirable. Therefore, the perspectives and the possibilities of growth of such relationship among Brazil and the Asian region are discussed, as a way of confirming the initiatives already existent.

Palavras-chave: Brasil - Ásia - Diplomacia

Key words: Brazil - Asia - Diplomacy 